\title{
Long-term Esophageal Cancer Survivor Treated by Bypass for Esophagobronchial Fistula After Chemoradiotherapy: A Case Report
}

\author{
MANATO OHSAWA, YOICHI HAMAI, YUTA IBUKI, MANABU EMI, \\ YOSHIHIRO MIYATA and MORIHITO OKADA \\ Department of Surgical Oncology, Hiroshima University, Hiroshima, Japan
}

\begin{abstract}
Background: An esophagorespiratory fistula $(E R F)$ is a fatal complication for patients with tracheobronchial invasion by esophageal cancer. We report the case of a long-term esophageal cancer survivor treated by esophageal bypass operation for ERF after chemoradiotherapy (CRT). Case Report: A 44-year-old man was treated with definitive CRT (i.e. 66 Gy radiotherapy, chemotherapy with cisplatin, and 5-fluorouracil) for unresectable locally advanced esophageal cancer with massive invasion of the left main bronchus. Although a complete clinical response was obtained, the patient developed pneumonia due to an ERF. Esophageal bypass operation was performed for symptomatic relief. The patient's symptoms improved and oral ingestion became possible. No recurrence has been seen for 12 years. Conclusion: Esophageal bypass surgery can help in relieving symptoms and might be associated with long-term survival for esophageal cancer patients with ERF after good response to CRT. Thus, bypass surgery is a useful option in the treatment for esophageal cancer with ERF.
\end{abstract}

Chemoradiotherapy (CRT) is the main treatment for unresectable locally advanced esophageal cancer (1-8). However, an esophagorespiratory fistula (ERF) occasionally occurs as a complication as a result of tumor reduction during or after CRT in patients with tracheobronchial invasion by esophageal cancer (7-10). ERF is a miserable and fatal complication for esophageal cancer patients. Once an ERF occurs, the patient inevitably develops pneumonia

Correspondence to: Yoichi Hamai, Department of Surgical Oncology, Hiroshima University, 1-2-3-Kasumi, Minami-ku, Hiroshima, 7348551, Japan. Tel: +81 822575869, Fax: +81 822567109, e-mail: yyhamai@hotmail.com

Key Words: Bypass, chemotherapy, esophagus, fistula, invasion, radiation, respiratory tract. and is unable consume anything orally. An ERF extremely worsens the patient's quality of life (QOL). Furthermore, it becomes difficult to continue further chemotherapy or radiation therapy for esophageal cancer. Therefore, ERFs significantly influence not only QOL but also prognosis of patients with esophageal cancer. Herein, we report a case of a long-term surviving patient with esophageal cancer who had left main bronchial invasion and was successfully treated with esophageal bypass for ERF after CRT.

\section{Case Report}

A 44-year-old man with esophageal cancer was referred to our hospital. The patient had locally advanced esophageal cancer with left bronchial invasion and lymph node metastasis. Chest $\mathrm{X}$-ray revealed extensive atelectasis of the lower lobe in left lung (Figure 1A), and the bulky primary tumor had massively invaded the left main bronchus and obstructed the bronchus on computed tomography image (Figure 1B and C). However, there was no distant metastasis. Therefore, he was diagnosed with unresectable locally advanced esophageal cancer of cT4b N1 M0 cStage IIIC according to the seventh TNM classification of the International Union Against Cancer (11). Definitive CRT with 66 Gy radiotherapy was administered and two cycles of chemotherapy with cisplatin and 5 -fluorouracil $\left(70 \mathrm{mg} / \mathrm{m}^{2} /\right.$ day of cisplatin on days 1 and 29 , and $700 \mathrm{mg} / \mathrm{m}^{2} /$ day of 5 fluorouracil on days 1-4 and 29-32). After the CRT, seven cycles of chemotherapy with cisplatin and 5-fluorouracil were added. Although a complete clinical response was obtained after these therapies, an ERF occurred (Figure 2). The patient developed severe cough and sputum with high fever. The patient was forced to fast. Esophageal gastric bypass surgery was performed for symptomatic relief.

The operation was performed using the esophageal bypass procedure as previously reported by us (Figure 3) (8). An upper midline abdominal incision was made, with the patient in the supine position. A gastric tube was prepared and used for reconstruction. The abdominal esophagus was divided, 
and a polyethylene tube was inserted into the esophagus and fixed via running absorbable sutures. The distal side of the polyethylene tube was brought out from the left hypochondrial region as tube esophagostomy.

Next, an incision was made in the left side of the neck, and the cervical esophagus was divided above the sternal notch. The esophageal stump was closed using a linear stapler. The gastric tube was then pulled up through the retrosternal route to the neck and anastomosed to the cervical esophagus using the hand-sewing technique. Drainage tubes were placed around the cervical anastomosis and in the left subphrenic space. A narrow 14-Fr drainage tube was inserted retrogradely through the tube esophagostomy into the remnant esophagus, and the tip of the narrow drainage tube was placed between the oral esophageal stump and the primary tumor to decompress and avoid rupture at the stump. The surgical duration was 3 hour 53 minutes, with $150 \mathrm{ml}$ blood loss.

The patient recovered uneventfully and resumed oral intake 9 days after the bypass operation. The polyethylene tube was removed on postoperative day 22 , while the narrow drainage tube was retained for drainage into the remnant esophagus. The patient was discharged 39 days after surgery. Currently, 12 years after the bypass operation, the patient is being followed-up at the outpatient clinic, and has not shown any relapse of esophageal cancer.

\section{Discussion}

Definitive CRT is the main treatment for unresectable locally advanced esophageal cancer with invasion to adjacent organs, and the prognosis of such patients is generally poor. Clinical complete responses after definitive CRT are observed in $24-32 \%$ of patients with T4 tumor, and the 5year survival is $7-14 \%$ (2-7). Therefore, only a few patients with locally advanced esophageal cancer are cured by remarkable tumor reduction by CRT.

In patients with tracheobronchial invasion by esophageal cancer, ERFs occasionally occur during or after CRT; the incidence of ERF in such patients is $20-30 \%$ (7-10). ERF frequently leads to severe pneumonia and extreme decline in the patient's QOL. Moreover, if ERFs occur during or after CRT, discontinuation of CRT is required or it is not possible to conduct additional chemotherapies after CRT due to the decline in the general status of the patient. Therefore, ERF is associated with the decline of not only of QOL but also the prognosis for patients with esophageal cancer. Appropriate countermeasures against ERF are extremely important for patients with tracheobronchial invasion.

We previously reported the usefulness of esophageal bypass surgery before CRT to prevent pneumonia and completion of CRT in a case in which ERF development was deemed possible during definitive CRT (8). In the present case, esophageal bypass was also useful for ERF even after
CRT because the patient was unable to consume orally without developing pneumonia, as reported during outpatient visits. Therefore, esophageal bypass should be considered as a treatment option for patients with esophageal cancer who have tracheobronchial invasion.

ERFs are usually treated palliatively via symptomatic treatment using esophageal stents, tracheobronchial stents, or a combination of stents (12-19). However, the clinical results of these stent therapies are not satisfactory. Most patients can eat only semisolid foods, and various complications after stent therapy have been reported, particularly in long-term followedup patients. Some life-threatening conditions, such as fistula formation, migration, and bleeding have also been reported after stent therapy (12-16). Even when stent placement and fistula closure are successful, restarting radiotherapy treatment is not recommended as it has high risks of life-threatening complications $(17,18)$. Furthermore, long-term results are not definitive for patients with locally advanced disease after complete tumor reduction by definitive CRT. Therefore, we must carefully consider the indication of stent therapy, especially for patients who show a good response to CRT.

Although esophageal bypass surgery increases the possibility of oral consumption for patients with ERF or esophageal stricture, there are also some postoperative complications associated with the surgery, such as anastomotic leakage, stricture, and recurrent nerve paralysis. In a few patients, oral intake is restricted for a certain period after surgery until complications are resolved. Moreover, the drainage of secretions from the remaining esophagus is a problem, for which internal and external esophageal drainage is required (20-23). However, external drainage might be better considering the risk of aspiration of digestive juices for patients with tracheobronchial invasion.

In conclusion, we report the long-term survival of a patient with T4 esophageal cancer with ERF 12 years after esophageal bypass surgery and definitive CRT. Esophageal bypass surgery is a useful option and can help in relieving symptoms and might be associated with improvement of prognosis for patients with esophageal cancer with ERFs.

\section{Declarations}

As this was a case report without Protected Health Information, ethics approval was not required.

\section{Consent for Publication}

The patient provided written consent for publication of the data.

\section{Availability of data and material}

The datasets generated and/or analyzed during the current study are not publicly available owing to patient confidentiality reasons but are available from the corresponding author on reasonable request. 


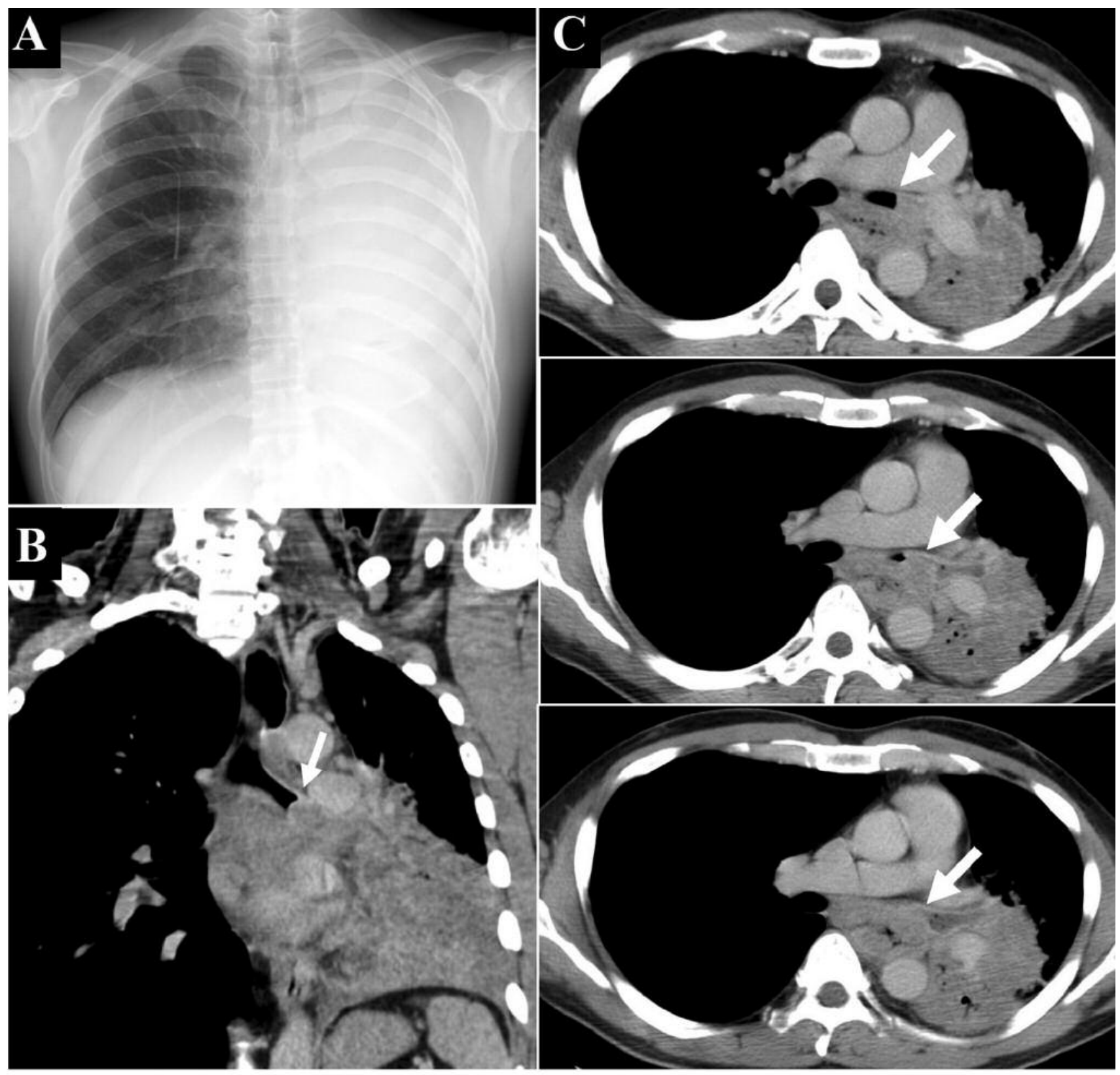

Figure 1. A: Chest X-ray showing extensive atelectasis of the left lung. B and C: Computed tomography imaging showing locally advanced esophageal cancer with invasion to the left main bronchus (arrow).

\section{Conflicts of Interests}

The Authors declare that they have no competing interests.

\section{Funding}

Not applicable.

\section{Authors' Contributions}

MO and YH drafted the article. MO, YH, YI, and ME contributed to patient care. $\mathrm{MO}$ and $\mathrm{YH}$ performed the literature search. MO, YH, YI, ME, and MO participated in the critical revision of the article. All the Authors read and approved the final article. 


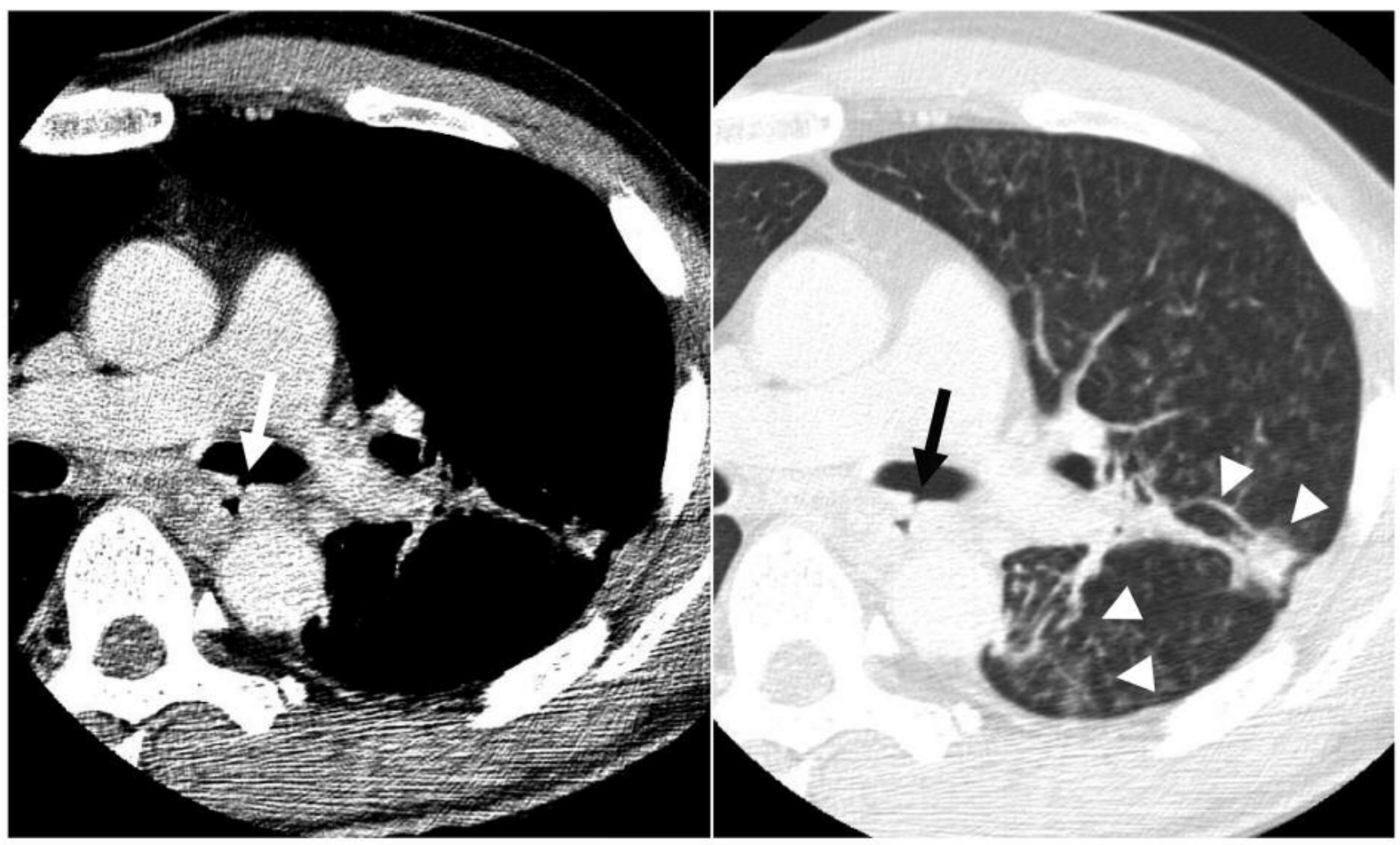

Figure 2. Computed tomography showing a fistula between the esophagus and left main bronchus (arrow) and pneumonia (arrowhead).

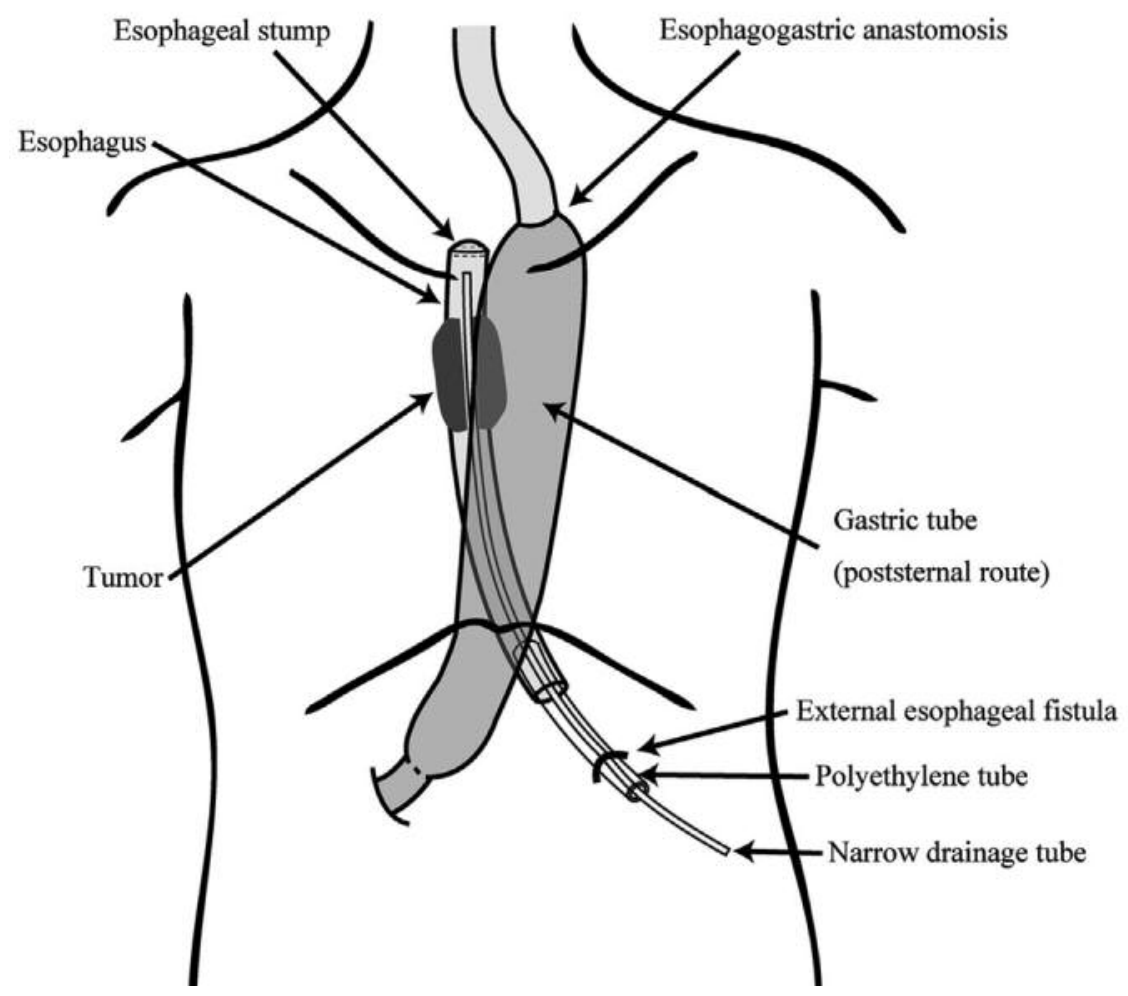

Figure 3. Procedure of esophageal bypass surgery as cited in our previous report (8). 


\section{References}

1 Hamai Y, Hihara J, Emi M, Taomoto J, Aoki Y, Kishimoto I, Ibuki Y and Okada M: Treatment outcomes and prognostic factors for thoracic esophageal cancer with clinical evidence of adjacent organ invasion. Anticancer Res 33(8): 3495-3502, 2013. PMID: 23898125.

2 Makino T and Doki Y: Treatment of T4 esophageal cancer. Definitive chemo-radiotherapy vs. chemo-radiotherapy followed by surgery. Ann Thorac Cardiovasc Surg 17(3): 221-228, 2011. PMID: 21697781. DOI: 10.5761/atcs.ra.11.01676

3 Seto Y, Chin K, Gomi K, Kozuka T, Fukuda T, Yamada K, Matsubara T, Tokunaga M, Kato Y, Yafune A and Yamaguchi T: Treatment of thoracic esophageal carcinoma invading adjacent structures. Cancer Sci 98(7): 937-942, 2007. PMID: 17512299. DOI: $10.1111 / \mathrm{j} .1349-7006.2007 .00479 . \mathrm{x}$

4 Fujita H, Sueyoshi S, Tanaka T, Tanaka Y, Matono S, Mori N, Shirouzu K, Yamana H, Suzuki G, Hayabuchi N and Matsui M: Esophagectomy: Is it necessary after chemoradiotherapy for a locally advanced T4 esophageal cancer? Prospective nonrandomized trial comparing chemoradiotherapy with surgery versus without surgery. World J Surg 29(1): 25-30, 2005. PMID: 15599735. DOI: $10.1007 / \mathrm{s} 00268-004-7590-2$

5 Nishimura Y, Suzuki M, Nakamatsu K, Kanamori S, Yagyu Y and Shigeoka $\mathrm{H}$ : Prospective trial of concurrent chemoradiotherapy with protracted infusion of 5-fluorouracil and cisplatin for T4 esophageal cancer with or without fistula. Int J Radiat Oncol Biol Phys 53(1): 134-139, 2002. PMID: 12007951. DOI: $10.1016 / \mathrm{S} 0360-3016(01) 02813-9$

6 Kaneko K, Ito H, Konishi K, Kurahashi T, Ito T, Katagiri A, Yamamoto T, Kitahara T, Mizutani Y, Ohtsu A and Mitamura K: Definitive chemoradiotherapy for patients with malignant stricture due to $\mathrm{T} 3$ or $\mathrm{T} 4$ squamous cell carcinoma of the oesophagus. Br J Cancer 88(1): 18-24, 2003. PMID: 12556953 DOI: $10.1038 \_s j . b j c .6600684$

7 Ohtsu A, Boku N, Muro K, Chin K, Muto M, Yoshida S, Satake M, Ishikura S, Ogino T, Miyata $\mathrm{Y}$ and Seki S: Definitive chemoradiotherapy for T4 and/or M1 lymph node squamous cell carcinoma of the esophagus. J Clin Oncol 17(9): 2915-2921, 1999. PMID: 10561371. DOI: 10.1200/JCO.1999.17.9.2915

8 Hihara J, Hamai Y, Emi M, Aoki Y, Taomoto J, Miyata Y and Okada M: Esophageal bypass operation prior to definitive chemoradiotherapy in advanced esophageal cancer with tracheobronchial invasion. Ann Thorac Surg 97(1): 290-295, 2014. PMID: 24200399. DOI: 10.1016/j.athoracsur.2013.08.060

9 Ishida K, Iizuka T, Ando N and Ide H: Phase II study of chemoradiotherapy for advanced squamous cell carcinoma of the thoracic esophagus: Nine Japanese institutions trial. Jpn J Clin Oncol 26(5): 310-315, 1996. PMID: 8895670. DOI: 10.1093/ oxfordjournals.jjco.a023238

10 Roussel A: Radiation therapy in esophageal carcinoma with bronchotracheal involvement (BTI): The Centre Francois Baclesse (CFB) experience. Proc Am Soc Clin Oncol 14: 190a, 1995.

11 TNM Classification of Malignant Tumours, Seventh Edition. Sobin LH, Gospodarowicz MK and Wittekind C (eds.). Chichester, UK, Blackwell: Wiley, 2009.

12 Abadal JM, Echenagusia A, Simo G and Camuñez F: Treatment of malignant esophagorespiratory fistulas with covered stents. Abdom Imaging 26(6): 565-569, 2001. PMID: 11911165. DOI: $10.1007 / \mathrm{s} 002610000193$
13 Nomori H, Horio H, Imazu Y and Suemasu K: Double stenting for esophageal and tracheobronchial stenoses. Ann Thorac Surg 70(6): 1803-1807, 2000. PMID: 11156075. DOI: 10.1016/S00 03-4975(00)02042-7

14 Nam DH, Shin JH, Song HY, Jung GS and Han YM: Malignant esophageal-tracheobronchial strictures: parallel placement of covered retrievable expandable nitinol stents. Acta Radiol 47(1): 3-9, 2006. PMID: 16498926. DOI: 10.1080/028418505003 34989

15 Lecleire S, Antonietti M, Di Fiore F, Ben-Soussan E, Bota S, Hellot MF, Thiberville L, Michel P, Lerebours E and Ducrotté P: Double stenting of oesophagus and airways in palliative treatment of patients with oesophageal cancer is efficient but associated with a high morbidity. Aliment Pharmacol Ther 25(8): 955-963, 2007. PMID: 17403000. DOI: 10.1111/j.1365-2036. 2007.03280.x

16 Hamai Y, Hihara J, Emi M, Okita R, Shimizu K and Okada M: Successful management of multiple esophagorespiratory fistulas using two types of stent: report of a case. Surg Today 41(4): 560-562, 2011. PMID: 21431494. DOI: 10.1007/s00595-0094298-9

17 Nishimura Y, Nagata K, Katano S, Hirota S, Nakamura K, Higuchi F, Soejima T and Sai H: Severe complications in advanced esophageal cancer treated with radiotherapy after intubation of esophageal stents: A questionnaire survey of the Japanese Society for Esophageal Diseases. Int J Radiat Oncol Biol Phys 56(5): 1327-1332, 2003. PMID: 12873677. DOI: 10.1016/S0360-3016(03)00198-6

18 Yakami M, Mitsumori M, Sai H, Nagata Y, Hiraoka M and Nishimura Y: Development of severe complications caused by stent placement followed by definitive radiation therapy for T4 esophageal cancer. Int J Clin Oncol 8(6): 395-398, 2003. PMID: 14663644. DOI: 10.1007/s10147-003-0356-2

19 Hamai Y, Hihara J, Emi M, Aoki Y, Miyata Y and Okada M: Airway stenting for malignant respiratory complications in esophageal cancer. Anticancer Res 32(5): 1785-1790, 2012. PMID: 22593462.

20 Postlethwait RW: Technique for isoperistaltic gastric tube for esophageal bypass. Ann Surg 189(6): 673-676, 1979. PMID: 453939. DOI: 10.1097/00000658-197906000-00001

21 Ong GB and Kwong KH: Management of malignant esophagobronchial fistula. Surgery 67(2): 293-301, 1970. PMID: 5411292.

22 Hirai T, Yamashita Y, Mukaida H, Kawano K, Toge T, Niimoto $\mathrm{M}$ and Hattori T: Bypass operation for advanced esophageal cancer - an analysis of 93 cases. Jpn J Surg 19(2): 182-188, 1989. PMID: 2724717. DOI: $10.1007 /$ BF02471583

23 Seto Y, Yamada K, Fukuda T, Hosoi N, Takebayashi R, Chin K, Kotsuka T, Gomi K and Yamaguchi T: Esophageal bypass using a gastric tube and a cardiostomy for malignant esophagorespiratory fistula. Am J Surg 193: 792-793, 2007. PMID: 1751229. DOI: $10.1016 /$ j.amjsurg .2006.07.023
Received May 23, 2019

Revised June 15, 2019

Accepted June 20, 2019 